\title{
Free triiodothyronine (T3) is negatively associated with fasting ghrelin serum levels in a population sample of euthyroid subjects
}

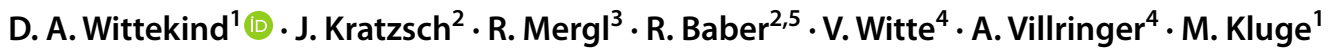

Received: 27 January 2021 / Accepted: 10 April 2021 / Published online: 21 April 2021

(c) The Author(s) 2021

\begin{abstract}
Purpose Ghrelin is an orexigenic peptide hormone secreted in times of stress and hunger. It is deeply involved in the regulation of metabolism and energy homeostasis, promoting energy intake and inhibiting energy expenditure on a metabolic level. In this regard, it has in many ways antagonistic effect on the thyroid hormones, which increase metabolism and thus energy expenditure. While there is reasonable evidence of a negative association between ghrelin and hormones of the hypothalamicpituitary-thyroid (HPT-) axis from studies in patients with thyroid dysfunction and small intervention studies, large-scale studies in healthy subjects are lacking. Therefore, we studied the relationship between total ghrelin serum levels and serum levels of the thyroid hormones in a large sample of euthyroid subjects.

Methods Total ghrelin, thyroid-stimulating hormone (TSH), free thyroxine (fT4) and free triiodothyronine (fT3) were determined after an overnight fast in 1666 subjects participating in a population-based cross-sectional study ('LIFE') including 10,000 adults. 1012 subjects were included in this analysis. Multiple linear regression analyses were performed.

Results FT3 was negatively associated with serum ghrelin; total sample: $\beta=-0.0001, p<0.001$; men: $\beta=-0.0002$, $p=0.013$; women: $\beta=-0.0001, p=0.010$, adjusted for age, BMI, alcohol consumption, serum levels of TSH and fT4 and smoking status. No associations were found between ghrelin serum levels and serum levels of fT4 or TSH.

Conclusion This is to date the largest study investigating the relationship between total serum ghrelin and thyroid hormones. The results point to a complex interaction and should initiate further research.
\end{abstract}

Keywords Ghrelin · Thyroid · Metabolism · Iodothyronine deiodinase $\cdot$ Homeostasis

D. A. Wittekind

dirkalexander.wittekind@medizin.uni-leipzig.de

1 Department of Psychiatry and Psychotherapy, University of Leipzig, Semmelweisstrasse 10, 04103 Leipzig, Germany

2 Institute of Laboratory Medicine, Clinical Chemistry and Molecular Diagnostics, University of Leipzig, Leipzig, Germany

3 Institute of Psychology, Universität der Bundeswehr München, Neubiberg, Germany

4 Department of Neurology, Max Planck Institute for Cognitive and Brain Sciences, Leipzig, Germany

5 LIFE, Leipzig Research Center for Civilization Diseases, University of Leipzig, Philipp-Rosenthal-Strasse 27, 04103 Leipzig, Germany

\section{Introduction}

Ghrelin is a 28-amino-acid peptide hormone that is predominantly synthesized in the stomach [1]. Ghrelin's receptor, the G-protein-coupled Growth-Hormone-SecretagogueReceptor (GHRS-1a) is widely expressed in a variety of tissues, but especially in endocrine tissue (e.g. thyroid) and the central nervous system [2]. Ghrelin binds to it after being acylated by the Ghrelin-O-acyl-transferase (GOAT) [3, 4]. Ghrelin is the only known peripheral orexigenic hormone which is secreted in times of hunger and when anticipating a meal [5, 6], promoting food intake and weight gain [7]. It is involved in glucose metabolism, suppressing pancreatic insulin secretion [8] and promoting hepatic secretion of insulin-like-growth-factor 1 and glucagon $[9,10]$. In addition, ghrelin has been shown to decrease thermogenesis and energy expenditure $[11,12]$. Combined, ghrelin acts toward a positive energy balance by increasing energy intake and decreasing energy expenditure. In line with this, ghrelin 
serum levels are elevated in underweight humans like in anorexia nervosa [13] and suppressed in obese individuals [14]. Furthermore, there is general agreement that ghrelin affects several endocrine axes: it exerts stimulatory effects on the hypothalamic-pituitary-adrenal axis (HPA) and the somatotropic axes $[6,15]$ and inhibitory effects on the hypothalamic-pituitary-gonadal (HPG) axis $[6,16]$. In contrast, ghrelin's effect on the hypothalamus-pituitary-thyroid (HPT) axis has not been acknowledged in the same way [6] although there is good evidence for an interplay between the ghrelin system and HPT axis [17, 18], with a majority of the evidence pointing to a negative association between ghrelin and thyroid hormones. For example, the administration of ghrelin suppressed TSH in animals [17] and humans [18].

Such an association is plausible since thyroid hormones exert to some extent opposing effects in the organism: they promote a negative energy balance by increasing metabolism and thermogenesis, thereby also increasing energy expenditure [19-21]. Thyroid hormones also play a key role in the maturation and differentiation of almost all tissues, including brain, liver, heart and muscle [22, 23]. Pituitary thyroidstimulating-hormone (TSH) stimulates the thyroid gland to produce thyroxine (T4) and to a lesser extent triiodthyronine (T3), which is about 4 times more biologically active than $\mathrm{T} 4$. The largest proportion of T3, however, is produced from $\mathrm{T} 4$ by mainly extra-thyroidal deiodinisation by a family of specialized enzymes, the deiodinases [23, 24].

Most studies have so far focused on patients suffering from thyroid dysfunction (e.g. [25, 26]). Interventional studies in healthy subjects, investigating ghrelin's effect on thyroid hormones and vice versa, were done in comparatively small samples [18, 27]. A large-scale study investigating the relationship between ghrelin serum levels and thyroid hormones is lacking. Therefore, we studied this relationship in a large, population-based sample of currently euthyroid subjects. We hypothesized that ghrelin serum levels are negatively associated with thyroid hormones.

\section{Methods}

\section{Study design and subjects}

Subjects were recruited in the context of the LIFE-AdultStudy (Leipzig Research Center for Civilization Diseases), a population-based cohort study with 10,000 participating adults mainly aged $40-79$ years. The sample was randomly recruited in the city of Leipzig in Germany (for details of the study design see Loeffler 2015 [28]). Blood samples were collected after an overnight fast including abstinence from smoking between 07:30 and 10:30 h. The blood samples have been immediately processed by the team of the LIFE pre-analytical laboratory which is part of the Leipzig Medical Biobank and send directly to the Institute of Laboratory Medicine, Clinical Chemistry, and Molecular Diagnostics (ILM) where direct analysis were carried out (fT3, fT4, TSH). Additional samples were frozen at $-80{ }^{\circ} \mathrm{C}$ until usage for ghrelin measurements.

When selecting study participants for ghrelin measurements, subjects with a history of stroke, multiple sclerosis or epilepsy were excluded. Total ghrelin was measured in 1666 subjects. From these, 151 subjects were excluded due to an incomplete data set, i.e. when any of the relevant variables was missing (e.g. ghrelin level, BMI, thyroid hormone levels, etc.). Subjects were excluded from the analysis if any of the thyroid hormones were not in the reference range (TSH 0.4-3.77 mU/l; fT4 12.8-20.4 pmol/1; fT3 3.1-6.79 pmol/l) [29, 30]. 295 subjects showed thyroid hormone levels outside of the reference range (for details see supplementary Table 1 ). A relatively high percentage of subjects showed thyroid hormone levels outside the reference range $(295 / 1515 \hat{=} 19.5 \%)$. Of these, TSH was altered in 123 subjects ( $8.1 \%) .172$ subjects (11.4\%) showed alterations only in fT3 and/or fT4 with TSH in the reference range. Alterations only in the free thyroid hormones, but not in TSH can be caused by several factors like altered levels of serum binding proteins [31] or displacement of free hormones from protein binding by certain drugs like furosemide, aspirin, non-steroidal antiinflammatory agents or heparin [31, 32]. Furthermore, other non-thyroidal disease states like chronic liver and renal disease [31,33], familial dysalbuminaemic hyperthyroxinaemia and in rare cases assay interference may lead to altered free thyroid hormone levels in commercial assays [31]. Subjects with a history of thyroid disease or current (self-) medication with thyroid-relevant medication were also excluded. Overall, 208 (17.0\%) further subjects had a history of thyroid disease. This high prevalence is in line with existing epidemiologic studies from Germany which estimated the prevalence of thyroid diseases at about 20-30\% [34] with as many as 33\% showing abnormal ultra-sound findings [34]. We interpret the high number of subjects with thyroid hormone levels outside of the reference range as a combination of the high prevalence of thyroid disease in the general population with the other factors discussed above. From the remaining individuals, nobody had current medication with thyroid relevant drugs, resulting in a study population of 1012 subjects (659 men, 353 women). Subjects with a gastro-intestinal pathology such as stomach/duodenal ulcer or inflammatory bowel disease (IBD) in the last 12 months were rare $(0.4 \%$ and $0.45 \%$, respectively) and were not excluded from the analysis, due to the low case number and the fact that these subjects were already in treatment for these conditions. All participants gave written informed consent to take part in the study. The procedures were conducted according to the 
Declaration of Helsinki and approved by the ethics committee of the University of Leipzig (registration-number: 263-2009-14122009).

\section{Ghrelin measurements}

All ghrelin measurements were done in serum by the use of a radioimmunoassay for total ghrelin (Mediagnost, Reutlingen Germany). Samples were not pre-treated with enzyme inhibitors or acidification. Due to this, only total ghrelin was measured, as it is much more stable than acyl-ghrelin. Sensitivity of the assay was $0.04 \mathrm{ng} / \mathrm{mL}$, mean intra-assay coefficients of variation were $2.7-4.3 \%$; interassay coefficients of variation were between 6.9 and $9.2 \%$ for the mean expected range of clinical data around 0.88 and $0.97 \mathrm{ng} / \mathrm{mL}$.

\section{TSH, fT4 and fT3 measurements}

Parameters of thyroid function (TSH, FT3; FT4) were measured by electrochemiluminescence assays (ECLIA) via Cobas 601 or 801 (Roche Diagnostics, Germany). Quality control (QC) data were calculated for 10 QC cycles with 15-110 runs per cycle over a representative range of 4 months over 4 years. The mean interassay coefficient of variation of the three measured biomarkers ranged between $2.25 \%$ and $3.11 \%$, the mean deviation from the target value was between 3.33 and $4.82 \%$.

\section{Acquisition of data on tobacco and alcohol consumption}

Tobacco consumption was assessed solely via self-administered questionnaire and interview. No biological verification method was used (like measurement of carbon monoxide in breath). Subjects were grouped into three categories: active smoker, former smoker and never-smoker. Active smokers were considered all those participants who had smoked regularly for at least 6 months consecutively in their lifetime and at least occasionally at the time of examination. Subjects who had smoked continuously for more than 6 months during their lifetime, but were not smoking at the time of assessment, were defined as former smokers. Cigarette equivalents (number per day) were calculated as follows: one cigarette equivalent was defined as $1 \mathrm{~g}$ of tobacco, 1 cigar was defined as $4 \mathrm{~g}$ of tobacco (i.e. 4 cigarette equivalents), 1 pipe as $3 \mathrm{~g}$ of tobacco (i.e. 3 cigarette equivalents), 1 cigarillo as $2 \mathrm{~g}$ of tobacco (i.e. 2 cigarette equivalents). For further information see Latza and others 2005 [35].

Frequency and amount of consumption of alcoholic beverages (i.e. beer/wine/spirits) during the last 12 months were semiquantitatively assessed using a self-administered food frequency and alcohol questionnaire (FFQ). Possible answers for the frequency of alcohol consumption were "multiple times a day", "daily", "multiple times a week", "once a week", "two to three times a month", "once a month or rarer" or "almost never". In addition, the amount of beverage consumption was assessed by defined categories. From the amount and frequency of alcoholic beverage as well as the average alcohol content of different beverages, the average consumption of pure alcohol ( $\mathrm{g} /$ day) was calculated.

\section{Assessment of BMI}

The BMI is defined as the body weight divided by the square of the body height $\left(\mathrm{kg} / \mathrm{m}^{2}\right)$. Body weight was measured with an electronic scale (SECA 701, Seca GmbH \& Co KG) with a precision of $0.01 \mathrm{~kg}$, height using a stadiometer (SECA 240) to the nearest $0.1 \mathrm{~cm}$ by trained staff according to standardized protocols.

\section{Statistical analysis}

A multivariate linear regression analysis was performed. Presuming an effect of ghrelin on TSH/fT4/fT3 levels, the independent variable was ghrelin and the dependent variable was TSH/fT4/fT3 levels. The analysis was adjusted for age (continuous variable), sex (categorical variable; reference category: male), BMI (continuous variable) and TSH/fT4/ fT3 levels respectively. In addition, the analysis was adjusted for smoking status (categorical variable; reference category: non-smokers) and alcohol consumption (continuous variable) both variables being associated with ghrelin levels $[36,37]$. Regression coefficients $(\beta)$ with $95 \%$ confidence intervals (CI) and corresponding $p$ values were calculated. In addition, standardized regression coefficients are supplied to represent the effects of variables independent of units. The same was true regarding the proportion of variance accounted for by the regression model $\left(R^{2}\right)$.

Furthermore, extreme-group comparisons were performed, i.e. Mann-Whitney U tests were used to test for statistical differences regarding FT3 levels between the highest and lowest quartile according to ghrelin serum levels for the total sample, but also for men and women separately.

The SPSS version 24.0 was used for the statistical analyses and the significance level $\alpha=0.05$ was chosen. All statistical tests were two-sided. Where appropriate, data are presented as mean (standard deviation) throughout.

\section{Results}

\section{Clinical data}

Description of the study sample can be found in Table 1. 
Table 1 Description of the sample

\begin{tabular}{|c|c|c|c|c|}
\hline Variable & Total sample $(n=1012)$ & Males $(n=659)(65.1 \%)$ & Females $(n=353)(34.9 \%)$ & $p$-value \\
\hline Ghrelin serum concentration, $\mathrm{pg} / \mathrm{ml}$, mean (SD) & $893.26(391.55)$ & $814.81(308.09)$ & $1039.72(479.43)$ & $<0.001 * * * \mathrm{a}$ \\
\hline Age, years, mean (SD) & $57.55(15.23)$ & $57.56(15.48)$ & $57.55(14.78)$ & $0.51^{\mathrm{a}}$ \\
\hline BMI, $\mathrm{kg} / \mathrm{m}^{2}$, mean (SD) & $27.09(4.35)$ & $27.32(3.99)$ & $26.65(4.92)$ & $<0.001 * * * \mathrm{a}$ \\
\hline Alcohol consumption, g/day, mean (SD) & $13.98(18.14)$ & $18.50(20.18)$ & $5.53(8.57)$ & $<0.001 * * * \mathrm{a}$ \\
\hline Non-smokers $(\%)$ & $853(84.3 \%)$ & $544(82.5 \%)$ & $309(87.5 \%)$ & $\mathbf{0 . 0 4} * \mathrm{~b}$ \\
\hline Active smokers (\%) & $159(15.7 \%)$ & $115(17.5 \%)$ & $44(12.5 \%)$ & - \\
\hline TSH concentration, mU/l, mean (SD) & $1.60(0.72)$ & $1.59(0.70)$ & $1.64(0.74)$ & $0.43^{\mathrm{a}}$ \\
\hline FT3 concentration, mU/l, mean (SD) & $5.08(0.56)$ & $5.21(0.54)$ & $4.83(0.52)$ & $<0.001 * * * \mathrm{c}$ \\
\hline FT4 concentration, mU/l, mean (SD) & $15.98(1.66)$ & $16.05(1.67)$ & $15.84(1.65)$ & $0.08^{\mathrm{a}}$ \\
\hline
\end{tabular}

SD Standard Deviation

$* p<0.05 ; * * p<0.01 ; * * * p<0.001$

${ }^{a}$ Due to non-normal distribution of the dependent variables (Kolmogorov-Smirnov-Test: $p<0.05$ ), a Mann-Whitney U test was performed to compute $\mathrm{p}$ values regarding ghrelin serum concentrations $(Z=-8.73)$, age $(Z=-0.66)$, BMI scores $(Z=-3.30)$, alcohol consumption $(Z=-$ 12.53), TSH concentrations $(Z=-0.79)$ and FT4 concentrations $(Z=-1.78)$

${ }^{\mathrm{b}} \mathrm{A}$ chi-square test for a two-by-two cross table $\left(\chi^{2}=4.32 ; \mathrm{df}=1\right)$ was applied

${ }^{\mathrm{c}} \mathrm{A} \mathrm{t}$ test for independent sample comparison $(t=10.64 ; \mathrm{df}=1,1010)$ was computed

\section{Association between thyroid hormones and ghrelin serum levels}

TSH and fT4 levels showed no association with total ghrelin serum levels (adjusted for age, sex, BMI, alcohol consumption, smoking status, fT3-levels and fT4- and TSH levels respectively). fT3 showed a significant negative association with ghrelin serum levels when adjusted for age, sex, BMI, alcohol consumption, smoking status, TSH- and fT4- levels $(\beta=-0.0001$, standardized $\beta=-0.102,95 \% \mathrm{CI}-0.0002$; $-0.00006 ; p<0.001$ ) (see also Fig. 1).

This effect was present in both men $(\beta=-0.0002$, standardized $\beta=-0.091 ; 95 \%$ CI $-0.0003 ;-0.00003$; $p=0.013)$ and women $(\beta=-0.0001$, standardized $\beta=-0.132 ; 95 \% \mathrm{CI}-0.0003 ;-0.00003 ; p=0.010)$, see also Table 2).

An extreme group comparison revealed significantly lower FT3 levels in individuals from the highest quartile group according to ghrelin serum levels than in those from the lowest quartile group $(Z=-4.27 ; p=0.00002)$. Corresponding differences in the male subgroup failed to be significant $(Z=-1.79 ; p=0.07)$. In women, the FT3 levels in subjects from the highest and lowest quartile group according to ghrelin serum levels were nearly identical (mean score: $4.8 \mathrm{pmol} / \mathrm{l} ; Z=0 ; p=1$ ) (for details see Table 3).
Fig. 1 Association between total ghrelin serum and FT3 serum levels, adjusted for BMI, age, alcohol consumption and smoking status

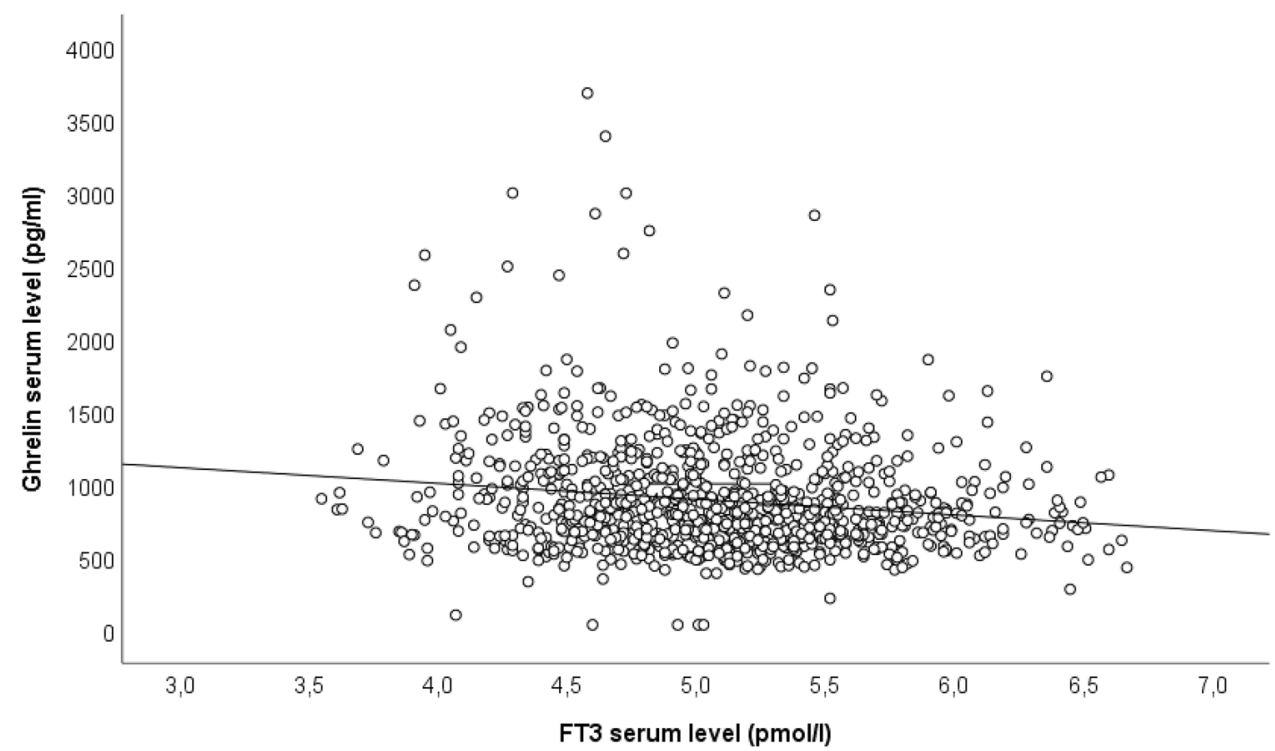


Table 2 Results of multiple linear regression analyses regarding the association between ghrelin serum levels and TSH, FT3 and FT4 concentrations in euthyreotic individuals

\begin{tabular}{|c|c|c|c|c|}
\hline Variables & Regression coefficient $\beta(95 \% \mathrm{CI})$ & Stan-dardized $\beta$ & $t$ & $p$ value \\
\hline \multicolumn{5}{|c|}{$\begin{array}{l}\text { TSH concentration in the total sample, } \mathrm{mU} / \mathrm{l}(N=1012) \\
\text { Corrected } R^{2}=0.057 ; F=8.70 ; p<0.001 * * *\end{array}$} \\
\hline Multivariate model $^{\mathrm{a}}$ & - & - & - & - \\
\hline Ghrelin serum levels & $0.0000051(-0.00011 ; 0.00012)$ & 0.003 & 0.09 & 0.93 \\
\hline Age & $-0.011(-0.014 ;-0.008)$ & -0.229 & -6.76 & $<0.001 * * *$ \\
\hline Sex & $0.028(-0.077 ; 0.133)$ & 0.019 & 0.52 & 0.60 \\
\hline Alcohol consumption & $-0.001(-0.003 ; 0.002)$ & -0.014 & -0.41 & 0.68 \\
\hline Smoking status & $-0.085(-0.147 ;-0.024)$ & -0.088 & -2.72 & $0.007 * *$ \\
\hline BMI & $0.010(-0.001 ; 0.020)$ & 0.058 & 1.79 & $0.08^{+}$ \\
\hline FT3 concentration & $0.046(-0.041 ; 0.134)$ & 0.036 & 1.04 & 0.30 \\
\hline FT4 concentration & $-0.049(-0.075 ;-0.022)$ & -0.113 & -3.58 & $<0.001 * * *$ \\
\hline \multicolumn{5}{|c|}{$\begin{array}{l}\text { FT3 concentration in the total sample, } \mathrm{mU} / \mathrm{l}(N=1012) \\
\text { Corrected } R^{2}=0.230 ; F=38.76 ; p<0.001^{* * *}\end{array}$} \\
\hline Multivariate model $^{\mathrm{a}}$ & - & - & - & - \\
\hline Ghrelin serum levels & $-0.00015(-0.00023 ;-0.000063)$ & -0.102 & -3.46 & $<0.001 * * *$ \\
\hline Age & $-0.010(-0.012 ;-0.008)$ & -0.269 & -8.92 & $<0.001 * * *$ \\
\hline Sex & $-0.308(-0.379 ;-0.237)$ & -0.263 & -8.46 & $<0.001 * * *$ \\
\hline Alcohol consumption & $0.00017(-0.002 ; 0.002)$ & 0.006 & 0.18 & 0.85 \\
\hline Smoking status & $0.061(0.018 ; 0.104)$ & 0.081 & 2.76 & $0.006 * *$ \\
\hline BMI & $-0.002(-0.010 ; 0.005)$ & -0.018 & -0.61 & 0.55 \\
\hline TSH concentration & $0.023(-0.021 ; 0.067)$ & 0.030 & 1.04 & 0.30 \\
\hline FT4 concentration & $0.065(0.046 ; 0.083)$ & 0.193 & 6.87 & $<0.001 * * *$ \\
\hline \multicolumn{5}{|c|}{$\begin{array}{l}\text { FT4 concentration in the total sample, } \mathrm{mU} / \mathrm{l}(\mathrm{N}=1012) \\
\text { Corrected } R^{2}=0.069 ; F=10.32 ; p<0.001 * * *\end{array}$} \\
\hline 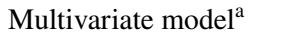 & - & - & - & - \\
\hline Ghrelin serum levels & $0.00014(-0.00013 ; 0.00041)$ & 0.033 & 1.02 & 0.31 \\
\hline Age & $0.003(-0.004 ; 0.011)$ & 0.032 & 0,93 & 0,35 \\
\hline Sex & $-0.141(-0.383 ; 0.100)$ & -0.041 & -1.15 & 0.25 \\
\hline Alcohol consumption & $-0.009(-0.015 ;-0.003)$ & -0.101 & -3.07 & $\mathbf{0 . 0 0 2} * *$ \\
\hline Smoking status & $-0.111(-0.253 ; 0.030)$ & -0.050 & -1.54 & 0.12 \\
\hline BMI & $-0.023(-0.047 ; 0.001)$ & -0.060 & -1.86 & $0.06^{+}$ \\
\hline TSH concentration & $-0.259(-0.401 ;-0.117)$ & -0.112 & -3.58 & $<0.001 * * *$ \\
\hline FT3 concentration & $0.692(0.495 ; 0.890)$ & 0.233 & 6.87 & $<0.001 * * *$ \\
\hline \multicolumn{5}{|c|}{$\begin{array}{l}\text { TSH concentration in men, } \mathrm{mU} / \mathrm{l}(n=659) \\
\text { Corrected } R^{2}=0.054 ; F=6.37 ; p<0.001 * * *\end{array}$} \\
\hline Multivariate model $^{\mathrm{a}}$ & - & - & - & - \\
\hline Ghrelin serum levels & $-0.000049(-0.00022 ; 0.000125)$ & -0.022 & -0.56 & 0.58 \\
\hline Age & $-0.011(-0.015 ;-0.007)$ & -0.242 & -5.69 & $<0.001 * * *$ \\
\hline Alcohol consumption & $-0.001(-0.004 ; 0.002)$ & -0.026 & -0.67 & 0.50 \\
\hline Smoking status & $-0.090(-0.164 ;-0.017)$ & -0.095 & -2.42 & $0.02 *$ \\
\hline BMI & $0.014(-0.000067 ; 0.028)$ & 0.079 & 1.95 & $0.051^{+}$ \\
\hline FT3 concentration & $-0.019(-0.126 ; 0.087)$ & -0.015 & -0.35 & 0.72 \\
\hline FT4 concentration & $-0.039(-0.072 ;-0.007)$ & -0.092 & -2.36 & $0.02 *$ \\
\hline \multicolumn{5}{|c|}{$\begin{array}{l}\text { FT3 concentration in men, mU/1 }(n=659) \\
\text { Corrected } R^{2}=0.151 ; F=17.70 ; p<0.001 * * *\end{array}$} \\
\hline Multivariate model $^{\mathrm{a}}$ & - & - & - & - \\
\hline Ghrelin serum levels & $-0.000159(-0.000284 ;-0.000034)$ & -0.091 & -2.49 & 0.013* \\
\hline Age & $-0.011(-0.014 ;-0.009)$ & -0.327 & -8.35 & $<0.001 * * *$ \\
\hline Alcohol consumption & $-0.000124(-0.002 ; 0.002)$ & -0.005 & -0.13 & 0.90 \\
\hline Smoking status & $0.065(0.012 ; 0.118)$ & 0.090 & 2.41 & $0.02 *$ \\
\hline BMI & $0.004(-0.006 ; 0.014)$ & 0.029 & 0.76 & 0.45 \\
\hline TSH concentration & $-0.010(-0.066 ; 0.046)$ & -0.013 & -0.35 & 0.72 \\
\hline
\end{tabular}


Table 2 (continued)

\begin{tabular}{|c|c|c|c|c|}
\hline Variables & Regression coefficient $\beta(95 \% \mathrm{CI})$ & Stan-dardized $ß$ & $t$ & $p$ value \\
\hline FT4 concentration & $0.057(0.034 ; 0.080)$ & 0.176 & 4.80 & $<0.001 * * *$ \\
\hline \multicolumn{5}{|c|}{$\begin{array}{l}\text { FT4 concentration in men, mU/l }(n=659) \\
\text { Corrected } R^{2}=0.063 ; F=7.36 ; p<0.001 * * *\end{array}$} \\
\hline Multivariate model $^{\mathrm{a}}$ & - & - & - & - \\
\hline Ghrelin serum levels & $0.000195(-0.000215 ; 0.000605)$ & 0.036 & 0.93 & 0.35 \\
\hline Age & $0.002(-0.007 ; 0.011)$ & 0.018 & 0.43 & 0.67 \\
\hline Alcohol consumption & $-0.009(-0.015 ;-0.003)$ & -0.112 & -2.89 & $0.004 * *$ \\
\hline Smoking status & $-0.040(-0.213 ; 0.133)$ & -0.018 & -0.45 & 0.65 \\
\hline BMI & $-0.044(-0.077 ;-0.011)$ & -0.106 & -2.63 & $0.009 * *$ \\
\hline TSH concentration & $-0.216(-0.397 ;-0.036)$ & -0.092 & -2.36 & $0.02 *$ \\
\hline FT3 concentration & $0.602(0.356 ; 0.848)$ & 0.194 & 4.80 & $<0.001 * * *$ \\
\hline \multicolumn{5}{|c|}{$\begin{array}{l}\text { TSH concentration in women, } \mathrm{mU} / \mathrm{l}(n=353) \\
\text { Corrected } R^{2}=0.063 ; F=4.38 ; p<0.001 * * *\end{array}$} \\
\hline Multivariate model $^{\mathrm{a}}$ & - & - & - & - \\
\hline Ghrelin serum levels & $0.000047(-0.000116 ; 0.00021)$ & 0.030 & 0.57 & 0.57 \\
\hline Age & $-0.011(-0.016 ;-0.005)$ & -0.212 & -3.70 & $<0.001 * * *$ \\
\hline Alcohol consumption & $0.003(-0.006 ; 0.012)$ & 0.034 & 0.64 & 0.52 \\
\hline Smoking status & $-0.082(-0.196 ; 0.031)$ & -0.078 & -1.42 & 0.16 \\
\hline BMI & $0.007(-0.009 ; 0.023)$ & 0.047 & 0.85 & 0.39 \\
\hline FT3 concentration & $0.173(0.016 ; 0.329)$ & 0.121 & 2.17 & $\mathbf{0 . 0 3 *}$ \\
\hline FT4 concentration & $-0.066(-0.113 ;-0.018)$ & -0.146 & -2.73 & $\mathbf{0 . 0 0 7} * *$ \\
\hline \multicolumn{5}{|c|}{$\begin{array}{l}\text { FT3 concentration in women, } \mathrm{mU} / \mathrm{l}(n=353) \\
\text { Corrected } R^{2}=0.139 ; F=9.13 ; p<0.001 * * *\end{array}$} \\
\hline Multivariate model $^{\mathrm{a}}$ & - & - & - & - \\
\hline Ghrelin serum levels & $-0.000143(-0.000251 ;-0.000034)$ & -0.132 & -2.59 & $0.010 *$ \\
\hline Age & $-0.007(-0.011 ;-0.003)$ & -0.206 & -3.75 & $<0.001 * * *$ \\
\hline Alcohol consumption & $0.002(-0.004 ; 0.008)$ & 0.027 & 0.53 & 0.60 \\
\hline Smoking status & $0.052(-0.024 ; 0.129)$ & 0.071 & 1.34 & 0.18 \\
\hline BMI & $-0.010(-0.021 ; 0.001)$ & -0.094 & -1.77 & $0.08^{+}$ \\
\hline TSH concentration & $0.078(0.007 ; 0.149)$ & 0.111 & 2.17 & $\mathbf{0 . 0 3 *}$ \\
\hline FT4 concentration & $0.081(0.050 ; 0.112)$ & 0.258 & 5.14 & $<0.001 * * *$ \\
\hline \multicolumn{5}{|c|}{$\begin{array}{l}\text { FT4 concentration in women, } \mathrm{mU} / \mathrm{l}(n=353) \\
\text { Corrected } R^{2}=0.076 ; F=5.15 ; p<0.001 * * *\end{array}$} \\
\hline Multivariate model $^{\mathrm{a}}$ & - & - & - & - \\
\hline Ghrelin serum levels & $0.000147(-0.000214 ; 0.000508)$ & 0.043 & 0.80 & 0.42 \\
\hline Age & $0.007(-0.006 ; 0.019)$ & 0.061 & 1.05 & 0.30 \\
\hline Alcohol consumption & $-0.005(-0.026 ; 0.015)$ & -0.028 & -0.53 & 0.60 \\
\hline Smoking status & $-0.239(-0.491 ; 0.013)$ & -0.102 & -1.87 & $0.06^{+}$ \\
\hline BMI & $0.004(-0.032 ; 0.040)$ & 0.012 & 0.22 & 0.83 \\
\hline TSH concentration & $-0.322(-0.555 ;-0.090)$ & -0.144 & -2.73 & $0.007 * *$ \\
\hline FT3 concentration & $0.880(0.544 ; 1.217)$ & 0.276 & 5.14 & $<0.001 * * *$ \\
\hline
\end{tabular}

$b$ regression coefficient, $\beta$ standardized regression coefficient, $C I$ confidence interval, $N / n$ sample sizes ${ }^{+} p<0.10 ; * p<0.05 ; * * p<0.01 ; * * * p<0.001$

${ }^{a}$ All multivariate linear regression models have been adjusted for age, sex (in total group analyses only), alcohol consumption, smoking status $(1=$ active smoking; $0=$ non-smoking), BMI scores and other thyroid hormone concentrations

\section{Discussion}

In this study, we determined the relationship between total ghrelin serum levels and serum levels of the thyroid hormones TSH, fT4 and fT3 in a large, population-based sample of euthyroid subjects. Ghrelin was negatively associated with serum levels of fT3 and showed no association with levels of TSH and fT4. In an extreme-group 
Table 3 Extreme-group-comparison of FT3 concentrations in the highest and lowest quartiles of ghrelin serum levels

\begin{tabular}{|c|c|c|c|c|c|c|c|c|c|}
\hline \multirow[t]{2}{*}{ Quar-tiles } & \multicolumn{3}{|c|}{ Ghrelin serum levels in $\mathrm{pg} / \mathrm{ml}$} & \multicolumn{3}{|c|}{ Mean FT3 concentrations (SD) (pmol/l) } & \multicolumn{3}{|l|}{$\mathrm{N}$} \\
\hline & All & Men & Wo-men & All & Men & Wo-men & All & Men & Wo-men \\
\hline Lowest: $<$ & 644.25 & 615 & 716 & $5.13(0.54)$ & $5.21(0.53)$ & $4.77(0.45)$ & 253 & 166 & 88 \\
\hline Highest: > & 1051 & 932 & 1245.5 & $4.93(0.54)$ & $5.12(0.54)$ & $4.81(0.53)$ & 254 & 168 & 88 \\
\hline- & - & - & - & $\begin{aligned} Z & =-4.27^{\mathrm{a}} \\
& p<0.001^{* * *}\end{aligned}$ & $Z=-1.79^{\mathrm{a}} p=0.073^{+}$ & $Z=0^{\mathrm{a}} p=1$ & - & - & - \\
\hline
\end{tabular}

$S D$ standard deviation

${ }^{+} \mathrm{p}<0.10 ; * p<0.05 ; * * p<0.01 ; * * * p<0.001$

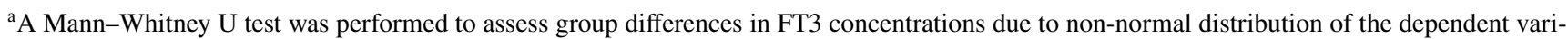
able (Kolmogorov-Smirnov-Test: $p<0.05$ )

comparison, there was a significant difference in fT3 levels between the highest and lowest quartile of serum ghrelin levels. Our findings are in line with studies indicating a negative association between ghrelin and thyroid hormones.

Current data suggests that there is a bidirectional antagonistic effect between ghrelin and thyroid hormones. In hypothyroid rats, ghrelin serum levels were elevated [38, 39]. Furthermore, ghrelin was shown to directly inhibit the production of thyroglobulin [40]. Likewise, hypothyroidism was associated with a higher production of ghrelin mRNA in the stomach mucosa of rats and hyperthyroidism with a lower concentration of mRNA [41]. In human studies, too, the vast majority of studies show higher ghrelin levels in hypothyroidism and lower ghrelin levels in hyperthyroidism (despite the often present increased appetite) [25, 26, $38,42-44]$, with some showing a direct negative correlation between fT3 and ghrelin [26, 45] and some showing only group effects $[38,44]$. Albeit, these are correlational studies from which no direct causal conclusion can be drawn. However, the few interventional studies show both, that ghrelin affects (predominantly inhibits) the HPT axis [17, 18, 27] and that TSH decreases ghrelin levels [46].

Ghrelin seems to affect the HPT-axis on multiple levels. Intervention studies in animals and humans suggest a suppressive effect of ghrelin at hypothalamic level resulting in decreased TSH levels $[17,18,27]$. The decrease in TSH in the study by Kluge et al. 2010 was accompanied by a subtle increase in fT4, which would be in line with a direct effect of ghrelin on the thyroid gland [47]. Thus, a suppression of TSH might have in part been caused by feedback inhibition of fT4 [18]. However, the authors argue that it is doubtful that the observed decrease in TSH is solely explained by the increase of fT4. Administration of much higher doses of fT4 led to a smaller decrease in TSH in another study [48] and ghrelin acts on hypothalamic neurons that decrease the activity of TRH-neurons [49-52]. These findings suggest a physiological relevance of ghrelin in the regulation of the HPT axis.
Our finding that ghrelin was only associated with fT3, but not fT4 and TSH contrasts to other, smaller studies where, if associations were found, they were between ghrelin and both fT4 and fT3 [25, 26, 38, 42-44]. This might be related to the type of study participants (patients with thyroid dysfunction vs. healthy subjects) and sample size with some studies being too small to unmask an existing association. Furthermore, our results direct the attention to another system regulating thyroid hormone concentration and metabolism, the system of the deiodinases. FT3 is the most biologically active form of thyroid hormones and is produced in the body in mainly two ways [24]: in the thyroid gland, together with fT4 in a ratio of approximately $1: 14[23,24]$ and through a system operating at the intracellular level, the iodothyronine deiodinases (DIO) [23]. Three deiodinase enzymes have been identified so far (DIO1, DIO2 and DIO3), which all catalyse the removal of an iodine atom both from fT4 and fT3. DIO2 acts only in an activating manner, converting fT4 to active fT3, while DIO3 actions are exactly opposite, deactivating fT3 and fT4 to diiodothyronine (T2) or reverse $\mathrm{T} 3$, respectively, which are both biologically inactive [53]. DIO1 is expressed in the liver and kidney and acts in an activating manner [54]. While the first mechanism accounts for approximately $20 \%$ of fT 3 plasma levels, the peripheral conversion provides the remaining $80 \%$ [55]. The regulation of fT 3 and fT 4 plasma levels is complex and seems to be an interaction between the action of the HPT-axis, thyroid hormone transporters and deiodinases [23]. The exact contribution of the deiodinase enzymes is debated, especially in humans, where data is very scarce [23]. DIO2 is thought to be the major source of plasma fT3 [23, 56], however, DIO1 is also believed to play a role, due to its location in the plasma membrane and the fact that fT3 produced by DIO1 exits the cell after $30 \mathrm{~min}$ compared to $8 \mathrm{~h}$ for DIO2 [23,57]. The contribution of DIO1 might even depend on whether the organism is in a euthyroid or hyperthyroid state $[23,58]$. In animals, DIO1 and DIO2 knockout (KO) mice showed fT3 levels 
within the reference range $[59,60]$ due to higher TSH levels and higher secretion of fT3 from the thyroid [61]. These results indicate the existence of compensatory mechanisms in the HPT-axis and in iodothyronine degradation, but also that the contribution of the thyroid gland to fT3 levels might be more pronounced in animals than in humans [23, 62, 63].

The deiodinase system allows the organism to modify the intracellular concentration of fT 3 at a single-cell level, depending on the current demand [23]. Under fasting conditions, the conversion of fT4 to fT 3 is reduced, for example by decreased expression of DIO1 in the liver and kidney [54, 64]. In addition, the rate of degradation of rT3 seems to be reduced [54,65], most likely as an energy-saving mechanism. Leptin seems to play a major role in this adaption [54] and it affects the deiodinase system in a stimulatory manner [66]. These are results from animal studies and might not exactly reflect the situation in humans.

Surprisingly, to our knowledge, so far no data exists investigating the relationship between ghrelin and the deiodinase system. While our correlational data does not allow for causal conclusions, it is an intriguing and biologically plausible thought that ghrelin might affect the activity of the deiodinase system as a further mechanism to reduce energy expenditure in fasting conditions. Assuming this is the case, then an inhibitory effect of ghrelin on DIO1 and DIO2 would seem plausible. Further research is needed to investigating the nature of the relationship between ghrelin and the DIO-system. This could lead to a more nuanced understanding of ghrelin's role in regulating metabolic adaption to hypocaloric and fasting states.

As outlined above, it is well documented that the HPTaxis adapts to fasting states. Fasting leads to decreased serum levels of fT3 after $24 \mathrm{~h}$ fasts by about $6 \%$ in humans [67], while ghrelin levels rise in fasting states [5]. However, this decrease in fT3 is accompanied by a more pronounced decrease in serum TSH levels by about $40 \%$ in the study by Basolo et al. and in previous studies [54, 67]. We did not, however, find an association of ghrelin levels and TSH. Furthermore, subjects in our study fasted merely overnight, instead of $24 \mathrm{~h}$. It is thus unlikely that the association between $\mathrm{fT} 3$ and ghrelin merely represents an unrelated fasting response.

Main limitation of the presented study is the cross-sectional design, not allowing to draw causal conclusions. Furthermore, only total ghrelin but not acylated ghrelin was determined and samples were not acidified or pretreated with protease inhibitors. The main strength of the study is the large sample size, which is a unique feature of this report. In addition, the study design and data collection were highly standardized.

\section{Conclusion}

This is to date the largest association study of total ghrelin serum levels and the thyroid hormones TSH, fT3 and fT4 in euthyroid subjects. The negative association of ghrelin serum levels with fT3, but not with fT4 and TSH, might be an initial indicator that ghrelin acts on the system of the deiodinases. Our results should initiate further research to facilitate a better understanding of the metabolic effects of ghrelin and its interaction with the thyroid system.

Supplementary Information The online version contains supplementary material available at https://doi.org/10.1007/s40618-021-01578-5.

\section{Acknowledgements None.}

Author contributions DAW: conceptualization and design, validation, project administration, writing-original draft. JK: investigation, writing-review and editing. RM: validation, writing — review and editing. RB: investigation, resources. VW: funding acquisition, resources, writing-review and editing. AV: funding acquisition, project administration. MK: conceptualization and design, validation, project administration, writing-original draft, supervision.

Funding Open Access funding enabled and organized by Projekt DEAL. This work was supported by LIFE—Leipzig Research Center for Civilization Diseases, University of Leipzig. LIFE is funded by means of the European Union, by means of the European Social Fund (ESF), by the European Regional Development Fund (ERDF), and by means of the Free State of Saxony within the framework of the excellence initiative. The author(s) acknowledge support from the German Research Foundation (DFG) and Universität Leipzig within the program of Open Access Publishing.

Data availability The data that support the findings of this study are available from the Leipzig Research Center for Civilisation Diseases (LIFE) but restrictions apply to the availability of these data, which were used under license (project number: PV_0358_Kluge) for the current study, and so are not publicly available. Data are, however, available from the authors upon reasonable request and with permission of LIFE.

\section{Declarations}

Conflict of interest The authors declares that there is no conflict of interest.

Ethical approval The procedures were conducted according to the Declaration of Helsinki and approved by the ethics committee of the University of Leipzig (registration-number: 263-2009-14122009).

Informed consent All participants gave written informed consent to take part in the study.

Open Access This article is licensed under a Creative Commons Attribution 4.0 International License, which permits use, sharing, adaptation, distribution and reproduction in any medium or format, as long as you give appropriate credit to the original author(s) and the source, provide a link to the Creative Commons licence, and indicate if changes were made. The images or other third party material in this article are included in the article's Creative Commons licence, unless indicated 
otherwise in a credit line to the material. If material is not included in the article's Creative Commons licence and your intended use is not permitted by statutory regulation or exceeds the permitted use, you will need to obtain permission directly from the copyright holder. To view a copy of this licence, visit http://creativecommons.org/licenses/by/4.0/.

\section{References}

1. Kojima M, Hosoda H, Date Y et al (1999) Ghrelin is a growthhormone-releasing acylated peptide from stomach. Nature 402:656-660. https://doi.org/10.1038/45230

2. Gnanapavan S, Kola B, Bustin SA et al (2002) The tissue distribution of the mRNA of ghrelin and subtypes of its receptor, GHS-R, in humans. J Clin Endocrinol Metab 87:2988. https:// doi.org/10.1210/jcem.87.6.8739

3. Gutierrez JA, Solenberg PJ, Perkins DR et al (2008) Ghrelin octanoylation mediated by an orphan lipid transferase. Proc Natl Acad Sci USA 105:6320-6325. https://doi.org/10.1073/pnas. 0800708105

4. Yang J, Brown MS, Liang G et al (2008) Identification of the acyltransferase that octanoylates ghrelin, an appetite-stimulating peptide hormone. Cell 132:387-396. https://doi.org/10.1016/j. cell.2008.01.017

5. Cummings DE, Purnell JQ, Frayo RS et al (2001) A preprandial rise in plasma ghrelin levels suggests a role in meal initiation in humans. Diabetes 50:1714-1719

6. Müller TD, Nogueiras R, Andermann ML et al (2015) Molecular Metabolism. Ghrelin Mol Metab 4:437-460. https://doi.org/10. 1016/j.molmet.2015.03.005

7. Tschöp M, Smiley DL, Heiman ML (2000) Ghrelin induces adiposity in rodents. Nature 407:908-913. https://doi.org/10.1038/ 35038090

8. Broglio F, Arvat E, Benso A et al (2001) Ghrelin, a natural GH secretagogue produced by the stomach, induces hyperglycemia and reduces insulin secretion in humans. J Clin Endocrinol Metab 86:5083-5086. https://doi.org/10.1210/jcem.86.10.8098

9. Chuang J-C, Sakata I, Kohno D et al (2011) Ghrelin directly stimulates glucagon secretion from pancreatic alpha-cells. Mol Endocrinol 25:1600-1611. https://doi.org/10.1210/me.2011-1001

10. Qader SS, Lundquist I, Ekelund M et al (2005) Ghrelin activates neuronal constitutive nitric oxide synthase in pancreatic islet cells while inhibiting insulin release and stimulating glucagon release. Regul Pept 128:51-56. https://doi.org/10.1016/j.regpep.2004.12. 018

11. Marzullo P, Verti B, Savia G et al (2004) The relationship between active ghrelin levels and human obesity involves alterations in resting energy expenditure. J Clin Endocrinol Metab 89:936-939

12. St-Pierre DH, Karelis AD, Cianflone K et al (2004) Relationship between ghrelin and energy expenditure in healthy young women. J Clin Endocrinol Metab 89:5993-5997. https://doi.org/10.1210/ jc.2004-0613

13. Otto B, Cuntz U, Fruehauf E et al (2001) Weight gain decreases elevated plasma ghrelin concentrations of patients with anorexia nervosa. Eur J Endocrinol 145:669-673. https://doi.org/10.1530/ eje. 0.1450669

14. Tschöp M, Weyer C, Tataranni PA et al (2001) Circulating ghrelin levels are decreased in human obesity. Diabetes 50:707-709

15. Takaya K, Ariyasu H, Kanamoto N et al (2000) Ghrelin strongly stimulates growth hormone $(\mathrm{GH})$ release in humans. J Clin Endocrinol Metab 85:4908-4911. https://doi.org/10.1210/jcem.85.12. 7167

16. Kluge M, Schüssler P, Schmidt D et al (2012) Ghrelin suppresses secretion of luteinizing hormone $(\mathrm{LH})$ and follicle-stimulating hormone (FSH) in women. J Clin Endocrinol Metab 97:E448E451. https://doi.org/10.1210/jc.2011-2607

17. Sosić-Jurjević B, Stevanović D, Milosević V et al (2009) Central ghrelin affects pituitary-thyroid axis: histomorphological and hormonal study in rats. Neuroendocrinology 89:327-336. https://doi. org/10.1159/000188603

18. Kluge M, Riedl S, Uhr M et al (2010) Ghrelin affects the hypothalamus-pituitary-thyroid axis in humans by increasing free thyroxine and decreasing TSH in plasma. Eur J Endocrinol 162:10591065. https://doi.org/10.1530/EJE-10-0094

19. Silva JE (2006) Thermogenic mechanisms and their hormonal regulation. Physiol Rev 86:435-464

20. Onur S, Haas V, Bosy-Westphal A et al (2005) L-tri-iodothyronine is a major determinant of resting energy expenditure in underweight patients with anorexia nervosa and during weight gain. Eur J Endocrinol 152:179-184. https://doi.org/10.1530/eje.1.01850

21. Kim B (2008) Thyroid hormone as a determinant of energy expenditure and the basal metabolic rate. Thyroid 18:141-144

22. Brent GA (1994) The molecular basis of thyroid hormone action. N Engl J Med 331:847-853

23. Luongo C, Dentice M, Salvatore D (2019) Deiodinases and their intricate role in thyroid hormone homeostasis. Nat Rev Endocrinol 15:479-488

24. Bianco AC, Salvatore D, Gereben B et al (2002) Biochemistry, cellular and molecular biology, and physiological roles of the iodothyronine selenodeiodinases. Endocr Rev 23:38-89. https:// doi.org/10.1210/edrv.23.1.0455

25. Mele C, Samà MT, Bisoffi AA et al (2019) Circulating adipokines and metabolic setting in differentiated thyroid cancer. Endocr Connect. https://doi.org/10.1530/EC-19-0262

26. Ruchala M, Gurgul E, Stangierski A et al (2014) Individual plasma ghrelin changes in the same patients in hyperthyroid, hypothyroid and euthyroid state. Peptides 51:31-34. https://doi. org/10.1016/j.peptides.2013.10.018

27. Kluge M, Schmidt D, Uhr M, Steiger A (2013) Ghrelin suppresses nocturnal secretion of luteinizing hormone (LH) and thyroid stimulating hormone (TSH) in patients with major depression. J Psychiatr Res 47:1236-1239. https://doi.org/10. 1016/j.jpsychires.2013.05.010

28. Loeffler M, Engel C, Ahnert P et al (2015) The LIFE-AdultStudy: objectives and design of a population-based cohort study with 10,000 deeply phenotyped adults in Germany. BMC Public Health 15:691. https://doi.org/10.1186/s12889-015-1983-z

29. Kußmaul T, Greiser KH, Haerting J et al (2014) Thyroid analytes TSH, FT3 and FT4 in serum of healthy elderly subjects as measured by the roche modular system: do we need age and gender dependent reference levels? Clin Lab 60:1551-1559. https://doi.org/10.7754/Clin.Lab.2014.130328

30. Kratzsch J, Fiedler GM, Leichtle A et al (2005) New reference intervals for thyrotropin and thyroid hormones based on national academy of clinical biochemistry criteria and regular ultrasonography of the thyroid. Clin Chem 51:1480-1486. https://doi.org/10.1373/clinchem.2004.047399

31. Koulouri O, Moran C, Halsall D et al (2013) Pitfalls in the measurement and interpretation of thyroid function tests. Best Pract Res Clin Endocrinol Metab 27:745-762. https://doi.org/ 10.1016/j.beem.2013.10.003

32. Stockigt JR, Lim CF (2009) Medications that distort in vitro tests of thyroid function, with particular reference to estimates of serum free thyroxine. Best Pract Res Clin Endocrinol Metab 23:753-767

33. Warner MH, Beckett GJ (2010) Mechanisms behind the nonthyroidal illness syndrome: an update. J Endocrinol 205:1-13

34. Reiners C, Wegscheider K, Schicha H et al (2004) Prevalence of thyroid disorders in the working population of Germany: 
ultrasonography screening in 96,278 unselected employees. Thyroid 14:926-932. https://doi.org/10.1089/thy.2004.14.926

35. Latza U, Hoffmann W, Terschüren C et al (2005) Rauchen als möglicher confounder in epidemiologischen studien: standardisierung der erhebung, quantifizierung und analyse. Das Gesundheitswes 67:795-802. https://doi.org/10.1055/s-2005-858807

36. Wittekind DA, Kratzsch J, Mergl R et al (2019) Higher fasting ghrelin serum levels in active smokers than in former and neversmokers. World J Biol Psychiatry. https://doi.org/10.1080/15622 975.2019.1671610

37. Wittekind DA, Kratzsch J, Mergl R et al (2018) Alcohol consumption is positively associated with fasting serum ghrelin in non-dependent adults: results from the population-based LIFEAdult-Study. Psychoneuroendocrinology 97:143-148. https://doi. org/10.1016/j.psyneuen.2018.07.021

38. Kokkinos A, Mourouzis I, Kyriaki D et al (2007) Possible implications of leptin, adiponectin and ghrelin in the regulation of energy homeostasis by thyroid hormone. Endocrine 32:30-32. https://doi. org/10.1007/s12020-007-9002-5

39. Chang Y-J, Hwu C-M, Yeh C-C et al (2014) Effects of subacute hypothyroidism on metabolism and growth-related molecules. Molecules 19:11178-11195. https://doi.org/10.3390/molecules1 90811178

40. Barington M, Brorson MM, Hofman-Bang J et al (2017) Ghrelinmediated inhibition of the TSH-stimulated function of differentiated human thyrocytes ex vivo. PLoS ONE 12:e0184992. https:// doi.org/10.1371/journal.pone.0184992

41. Caminos JE, Seoane LM, Tovar SA et al (2002) Influence of thyroid status and growth hormone deficiency on ghrelin. Eur J Endocrinol 147:159-163. https://doi.org/10.1530/eje.0.1470159

42. Kosowicz J, Baumann-Antczak A, Ruchaa M et al (2011) Thyroid hormones affect plasma ghrelin and obestatin levels. Horm Metab Res 43:121-125. https://doi.org/10.1055/s-0030-1269853

43. Biyikli HH, Arduc A, Isik S, Ozuguz U, Caner S, Dogru F et al (2014) Assessing the relationship between serum ghrelin levels and metabolic parameters and autoimmunity in patients with euthyroid hashimoto's thyroiditis. Endocr Pract 20:818-824. https://doi.org/10.4158/EP13469.OR

44. Giménez-Palop O, Giménez-Pérez G, Mauricio D et al (2005) Circulating ghrelin in thyroid dysfunction is related to insulin resistance and not to hunger, food intake or anthropometric changes. Eur J Endocrinol 153:73-79. https://doi.org/10.1530/eje.1.01934

45. Tanda ML, Lombardi V, Genovesi M et al (2009) Plasma total and acylated Ghrelin concentrations in patients with clinical and subclinical thyroid dysfunction. J Endocrinol Invest 32:74-78. https://doi.org/10.1007/BF03345683

46. Ciuoli C, Brusco L, Theodoropoulou A et al (2011) Effects of acute recombinant human TSH on serum ghrelin levels. Front Endocrinol (Lausanne). https://doi.org/10.3389/fendo.2011.00094

47. Park YJ, Lee YJ, Kim SH et al (2008) Ghrelin enhances the proliferating effect of thyroid stimulating hormone in FRTL-5 thyroid cells. Mol Cell Endocrinol 285:19-25. https://doi.org/10.1016/j. mce.2008.01.003

48. Benhadi N, Fliers E, Visser TJ et al (2010) Pilot study on the assessment of the setpoint of the hypothalamus- pituitary-thyroid axis in healthy volunteers. Eur J Endocrinol 162:323-329. https:// doi.org/10.1530/EJE-09-0655

49. Chen HY, Trumbauer ME, Chen AS et al (2004) Orexigenic action of peripheral ghrelin is mediated by neuropeptide $\mathrm{Y}$ and agoutirelated protein. Endocrinology 145:2607-2612. https://doi.org/ 10.1210/en.2003-1596

50. Kamegai J, Tamura H, Shimizu T et al (2001) Chronic central infusion of ghrelin increases hypothalamic neuropeptide $\mathrm{Y}$ and Agouti-related protein mRNA levels and body weight in rats. Diabetes 50:2438-2443
51. Fekete C, Lechan RM (2007) Negative feedback regulation of hypophysiotropic thyrotropin-releasing hormone (TRH) synthesizing neurons: role of neuronal afferents and type 2 deiodinase. Front Neuroendocrinol 28:97-114

52. Fekete C, Singru PS, Sanchez E et al (2006) Differential effects of central leptin, insulin, or glucose administration during fasting on the hypothalamic-pituitary-thyroid axis and feeding-related neurons in the arcuate nucleus. Endocrinology 147:520-529. https:// doi.org/10.1210/en.2005-0956

53. Gereben B, Zavacki AM, Ribich S et al (2008) Cellular and molecular basis of deiodinase-regulated thyroid hormone signaling. Endocr Rev 29:898-938

54. Boelen A, Wiersinga WM, Fliers E (2008) Fasting-induced changes in the hypothalamus-pituitary-thyroid axis. Thyroid 18:123-129

55. Pilo A, Iervasi G, Vitek F et al (1990) Thyroidal and peripheral production of 3,5,3'-triiodothyronine in humans by multicompartmental analysis. Am J Physiol Endocrinol Metab. https://doi.org/ 10.1152/ajpendo.1990.258.4.e715

56. Maia AL, Kim BW, Huang SA et al (2005) Type 2 iodothyronine deiodinase is the major source of plasma T3 in euthyroid humans. J Clin Invest 115:2524-2533. https://doi.org/10.1172/JCI25083

57. Bianco AC, Silva JE (1987) Nuclear 3,5,3\|-triiodothyronine (t3) in brown adipose tissue: receptor occupancy and sources of $\mathrm{t} 3$ as determined by in vivo techniques. Endocrinology 120:55-62. https://doi.org/10.1210/endo-120-1-55

58. Koenig RJ (2005) Regulation of type 1 iodothyronine deiodinase in health and disease. Thyroid 15:835-840

59. Schneider MJ, Fiering SN, Thai B et al (2006) Targeted disruption of the type 1 selenodeiodinase gene (Dio1) results in marked changes in thyroid hormone economy in mice. Endocrinology 147:580-589. https://doi.org/10.1210/en.2005-0739

60. Schneider MJ, Fiering SN, Pallud SE et al (2001) Targeted disruption of the type 2 selenodeiodinase gene (Dio2) results in a phenotype of pituitary resistance to T4. Mol Endocrinol 15:2137-2148. https://doi.org/10.1210/mend.15.12.0740

61. Galton VA, Schneider MJ, Clark AS, St. Germain DL (2009) Life without thyroxine to 3,5,3'-triiodothyronine conversion: studies in mice devoid of the 5'-deiodinases. Endocrinology 150:2957-2963. https://doi.org/10.1210/en.2008-1572

62. Chanoine JP, Braverman LE, Farwell AP et al (1993) The thyroid gland is a major source of circulating T3 in the rat. J Clin Invest 91:2709-2713. https://doi.org/10.1172/JCI116510

63. Nguyen TT, Chapa F, Distefano JJ (1998) Direct measurement of the contributions of type I and type II 5'- deiodinases to whole body steady state 3,5,3'-triiodothyronine production from thyroxine in the rat. Endocrinology 139:4626-4633. https://doi.org/10. 1210/endo.139.11.6323

64. Docter R, Krenning EP, De Jong M, Hennemann G (1993) The sick euthyroid syndrome: changes in thyroid hormone serum parameters and hormone metabolism. Clin Endocrinol (Oxf) 39:499-518

65. Lopresti JS, Gray D, Nicoloff JT (1991) Influence of fasting and refeeding on 3, 3', 5'-triiodothyronine metabolism in man. J Clin Endocrinol Metab 72:130-136. https://doi.org/10.1210/ jcem-72-1-130

66. Cabanelas A, Lisboa PC, Moura EG, Pazos Moura CC (2006) Leptin acute modulation of the 5'-deiodinase activities in hypothalamus, pituitary and brown adipose tissue of fed rats. Horm Metab Res 38:481-485. https://doi.org/10.1055/s-2006-949527

67. Basolo A, Begaye B, Hollstein T et al (2019) Effects of short-term fasting and different overfeeding diets on thyroid hormones in healthy humans. Thyroid 29:1209-1212. https://doi.org/10.1089/ thy. 2019.0237

Publisher's Note Springer Nature remains neutral with regard to jurisdictional claims in published maps and institutional affiliations. 